\section{Armchair geology}

THE mere statistics of wilderness areas are impressive enough. The Earth's surface contains something like $18 \times 10^{\mathrm{f}}$ $\mathrm{km}^{2}$ of desert, about half of which is accounted for by Australia and the Sahara. And to this $12 \%$ of the total land surface must be added $11 \%$ under permanent ice cover, $9 \%$ covered with mountain, a further $9 \%$ of cold and waterlogged tundra, and $29 \%$ of otherwise uncultivable continent comprising semi-arid regions, bare rock, frost-prone areas, and so on. Taking the oceans into account now, only $9 \%$ of the Earth's surface can be cultivated and only about a third of that is actually tilled.

To be able (by courtesy of the BBC) to escape from man's narrow well-beaten tracks from time to time to make a series of television programmes about the world's varied wildernesses, Anthony Smith, the naturalist-broadcaster (as opposed to the political scientist-broadcaster and the medical journalist of the same name), was indeed privileged. His book, Wilderness (Allen and Unwin: Hemel Hempstead, UK, £7.50), though obviously a spin-off from the series, is not the "book of the film" in the usual sense but, rather, an independent personal account involving a mixture of description, observation, reaction, interpretation, background and anecdote relating to his visits to the world's largest ice-sheet (Antarctica), the biggest tropical forest (Brazil), a large desert (central Australia), the highest mountain range (Himalayas), the tundra (northern Canada) and the most extensive swamp (Sudd).

"Discovering a nest", says Smith at one stage with unconscious irony, "is more rewarding than being shown ten of them." Precisely - which is why all travel books are inherently unsatisfactory. Whether you like or dislike this one will depend on whether or not you can bear to visit places through another person's words. Generally I cannot; but because of the unusual nature of the places, I managed to overcome the resistance in this case and was rewarded with a pleasant afternoon, not least because of the superb colour plates.

But if Smith's book is the closest most of us are likely to get to the true wilderness, the phenomena described by P. J. Banyard in his Natural Wonders of the World (Orbis: London, £5.95) are more accessible. as they lie mainly within man's proportionally small terrestrial domain. Landforms, ice patterns, water displays, atmospheric phenomena, gurglings from the Earth's interior, exotic flower arrangements-they are all here in a combination of pleasing pictures and straightforwardly factual text. It makes for a nice browse; but there is a sense of deja vu about it all, for what we are looking at is just the latest vetsion of the world picture book that grandma bought us for our eleventh birthdays. There is little one can fault Banyard on, lest it be lack of inspiration; but it is at times like this that one comes to appreciate Anthony Smith's sense of personal quest and involvement.

Involvement of another kind is inherent in Alan Woolley's Illustrated Encyclopaedia of the Mineral Kingdom, (Hamlyn: Feltham, UK, £5.95) for mineralogy in its simplest form, the collection of minerals, is the most popular of geology's branches, at least as far as the amateur is concerned. I presume that this new Hamlyn encyclopaedia has been produced largely with the non-geologist in mind, but non-mineralogical Earth scientists will also find it useful as far as it goes. Its main defect as far as working geologists are concerned is that it only goes as far as about 300 of the world's 2500 or so minerals (generally the most common and widely distributed but including a few rarer ones of greater than usual interest to mineral collectors).

For the chosen 300, however, all the essential information is given (composition, hardness, lustre, occurrence, and so on) and the colour photographs are good. On the other hand, the book is far from being a mere list, for there are summary chapters on the Earth's structure and history, crustal composition, minerals and rocks in their geological environ-

\section{For budding holographers}

Unckerstanding Holography. By Michacl Wenyon. Pp. 176. (David and Charles: Newton Abbot and London, 1978.) £5.50.

THIs book is intended for the general reader and starts with two chapters about light and the laser in which various ideas relating to waves, coherence, interference, stereoscopic images, stimulated and spontaneous emission, and so on, are introduced in a non-mathematical manner. There follows a short digression on the applications of lasers in such fields as medicine and laser light shows before a discussion of the principles of holography. The basic ideas of holography are considered from the diffraction grating approach, and a well informed reader may have thought that more insight into the process would have been obtained, had the idea of the grating been extended to include the Fresnel zone plate. The effects of the size and spectral content of the light source used in the reconstruction process are, surprisingly, not considered in detail.

The chapter on display holography makes entertaining reading and there are many illustrations (necessarily two dimen- ments, crystals, gemstones, economic minerals and the building of a mineral collection. This book too is but a variant of its numerous predecessors over the years; but within its stated limitations it is far more authoritative and better produced than most.

Aggregates of minerals (that is, rocks) are generally less colourful than some of the pure minerals and thus less popular as collectors' items. The most colourful specimens in Rocks of the World, (Pergamon: Oxford, $£ 15$ ), which is not a book but a neatly-mounted set of 36 of the world's most basic rocks, are the laterite, the serpentinite and the ignimbrite; but despite the preponderance of greys the collection is a fascinating one, not least by the way it suddenly appears in one's hand without all the effort of collecting individual samples. Armchair geologists of the world will rejoice; but schoolteachers will not be displeased either, for a good collection of basic rocks is, of course, essential for beginning geology classes. The samples are rather small (up to about $4 \mathrm{~cm}$ across) and, being mounted, cannot easily be handled by a group of students. As a purely visual display, however, the set can hardly be faulted.

Peter J. Smith

Peter J. Smith is Reader in the Depart ment of Earth Sciences at the Open University, Milton Keynes, UK.

sional) of what has been achieved in this field. It is possible to make holographic pendants, three dimensional abstract light patterns and rainbow cylinder holograms; and even Salvador Dali has shown an interest in the technique. As for the future of holography, the author tells us that holographic movies already exist and could well become a viable proposition on a large scale. There is, however, a sinister comment that "life-like 3D movies could also be used in the future for psychological conditioning or brainwashing". Holographic television, it seems, is unlikely to be realised in the near future. Apart from its obvious entertainment value, holography can be used in a more serious vein, as illustrated by the accounts of applications in the study of the vibration modes of musical instruments and the testing of car tyres.

The final chapter is an account of how to make your own holograms with simple equipment. Perhaps the easiest way of making a simple hologram is to use conventional fine grain film and to ensure there is a small angle between the object and the reference beam. It is a pity there is no mention of this experiment, if for no other reason than the relative cheapness of the photographic material. Also the double exposure scatter plate experiments could have been described as they are easy 